\title{
Pelatihan Pemetaan Potensi Wisata Berbasis Pemberdayaan Masyarakat Kabupaten Maros Sulawesi Selatan
}

\author{
Harifuddin Halim*1, Ibrahim², Rasyidah Zainuddin ${ }^{3}$ \\ ${ }^{1}$ Sosiologi.Universitas Bosowa Makassar \\ ${ }^{2}$ Akuntansi. STIEM Bongaya Makassar \\ ${ }^{3}$ Sosiologi Pendidikan.STKIP DDI Mamuju \\ *e-mail: harifuddin.halim@universitasbosowa.ac.id 1, \\ ibrahimkajur@gmail.com ${ }^{2}$,georgiana.aan07@gmail.com ${ }^{3}$
}

\begin{abstract}
Maros Regency is a culturally rich area with beautiful natural potential that has the opportunity to become a tourism asset for the local government. The amount of tourism potential is not necessarily significant to the level of community participation in local tourism development. Therefore, it is considered necessary to empower the community so that they are aware of and involved in the development of local tourism which can then have an impact on their economic life. This article aims to describe community empowerment activities through tourism mapping training in Maros Regency. This service activity is the result of a collaboration between ADPERTISI and the Maros Regency Government with the training location in Bontoa District. This service was attended by approximately 40 community members from various groups such as youth groups, groups of lovers of tourist villages. This training aims to (1) map the tourism potential in Maros Regency, especially in Bontoa Subdistrict, and (2) make the public aware of their potential awareness to develop for the better. The training was conducted using lecture, question and answer, discussion, and FGD methods. The results of this training resulted in the following outcomes: (1) the birth of a mapping of local tourism potential in the Bontoa sub-district, (2) the birth of many community ideas about social issues related to tourism, (3) The emergence of a willingness from community groups to be seriously involved in developing tourism potential their local.
\end{abstract}

Keywords:Service, Training, Empowerment, Tourism

\begin{abstract}
Abstrak
Kabupaten Maros merupakan wilayah yang kaya budaya dengan potensi alam yang indah yang berpeluang menjadi aset wisata pemerintah setempat. Banyaknya potensi wisata tersebut tidak serta merta signifikan terhadap tingkat partisipasi masyarakatnya terhadap pengembangan pariwisata lokal. Oleh karena itulah, dianggap perlu untuk memberdayakan masyarakat agar mereka sadar dan terlibat dalam pengembangan pariwisata lokal yang kemudian dapat berdampak terhadap kehidupan ekonomi mereka. Artikel ini bertujuan untuk mendeskripsikan kegiatan pemberdayaan masyarakat melalui pelatihan pemetaan pariwisata di Kabupaten Maros. Kegiatan pengabdian ini merupakan hasil kerjasama antara ADPERTISI dengan Pemerintah Kabupaten Maros dengan lokasi pelatihan di Kecamatan Bontoa. Pengabdian ini dihadiri oleh kurang lebih 40 warga masyarakat berasal dari berbagai kelompok seperti kelompok karang taruna, kelompok pencinta desa wisata. Pelatihan ini bertujuan (1) memetakan potensi wisata di Kabupaten Maros khususnya di Kecamatan Bontoa, dan (2) menyadarkan masyarakat atas potensi kesadaran yang mereka miliki untuk berkembang menjadi lebih baik. Pelatihan dilakukan dengan metode ceramah, tanya jawab, diskusi, dan FGD. Hasil pelatihan ini menghasilkan luaran-luaran sebagai berikut: (1) lahirnya pemetaan potensi wisata lokal di kecamatan Bontoa, (2) lahirnya banyak gagasan masyarakat tentang persoalan sosial terkait pariwisata, (3) Lahirnya kesediaan kelompok masyarakat untuk terlibat secara serius dalam mengembangkan potensi wisata lokal mereka.
\end{abstract}

Kata kunci: Pengabdian, Pelatihan, Pemberdayaan, Pariwisata 


\section{PENDAHULUAN}

Pandemi Covid-19 berdampak luas dan massif pada seluruh bidang kehidupan manusia terlebih lagi bidang pariwisata. Kebijakan pemerintah Republik Indonesia memberlakukan program Lockdown dengan melarang semua orang asing memasuki wilayah Indonesia secara signifikan berakibat langsung terhadap turunnya jumlah wisatawan asing dan domestik yang berkunjung ke obyek wisata di Indonesia. Situasi ini pun berdampak pada bidang-bidang terkait pariwisata lainnya seperti perhotelan, restoran, penjualan cindera mata, dan sebagainya(A.A.A Ribeka Martha Purwahita et al., 2021; Ananta and Rizkon, 2020).

Pembatasan sosial menyebabkan roda bisnis mengalami perlambatan, banyak bisnis berhenti terutama bisnis yang terkait dengan pariwisata(Ismoyo, 2021). Pedagang cindera mata berhenti karena tidak ada pengunjung ke lokasi wisata. Pemasok barang kerajinan cindera mata juga berhenti karena tidak ada lagi yang memesan kerajinan mereka. Penghasilan mereka pun tidak ada sementara mereka tetap membutuhkan biaya yang makin besar. Situasi ini pun memaksa masyarakat berpikir untuk mencari alternatif lain yang belum pernah mereka lakukan.

Bagi sebagian besar pemerintah kabupaten di Sulawesi Selatan, situasi covid tersebut mereka manfaatkan untuk melakukan pembenahan terhadap bidang pariwisata kabupaten(Kendar, 2021). Ada yang melakukan renovasi sarana dan prasarana pariwisata, ada yang menyusun ulang program pariwisata, ada yang menambah lokasi wisata, dan ada juga yang melakukan pemetaan terhadap potensi wisata lokalnya.

Kabupaten Maros Sulawesi Selatan merupakan salah satu daerah yang memiliki potensi wisata yang besar. Wilayah ini memiliki dua obyek wisata yang terkenal di seluruh dunia yaitu wisata gunung karst terbesar nomor dua dunia(Kinapsi, 2021; Kumparan, 2018; Puspadini, 2021), dan wisata goa dengan ratusan jenis kupu-kupu langka di dunia(Poerwanto, 2019; Yolanda, 2019).

Dalam konteks pembangunan, pemerintah kabupaten harus melakukan pengembangan yang terus-menerus. Melalui Dinas Pariwisata,pengembangan pariwisata terus dikembangkan sehingga muncullah potensi wisata baru seperti, wisata pantai tak bertepi, wisata sungai, wisata gunung, wisata religius, pengembangan desa wisata, dan sebagainya(Redaksi, 2021). Tetapi, program-program tersebut baru sampai pada membaca potensi yang berpeluang untuk dikembangkan tetapi belum sampai pada level pemetaan potensi secara serius.

Mengikuti trend pembangunan di era Jokowi yang berbasis partisipasi masyarakat, maka pembangunan pariwisata di Maros juga mengusung konsep pemberdayaan masyarakat. Hal tersebut diwujudkan dengan melibatkan kelompok 'Karang Taruna' serta membentuk kelompok Pemuda Pencinta Wisata di masingmasing wilayah Desa dan Kelurahan. Kelompok ini membantu kepala desa atau kelurahan mengelola potensi wisata lokal. Melalui cara ini, maka pemberdayaan masyarakat benar-benar terwujud dalam pembangunan pariwisata.

Secara prinsip, pemberdayaan menyasar kelompok masyarakat yang tidak berdaya secara sosial ekonomi. Masyarakat yang tidak memiliki pendapatan yang memadai untuk membiayai kehidupan keluarganya. Mereka juga tidak memiliki relasi sosial yang signifikan yang berdampak terhadap kesejahteraan mereka. Namun demikian, di balik keterbatasan aspek sosial ekonomi tersebut adalah kesadaran individu kelompok masyarakat yang belum terpicu, belum tergali untuk memanfaatkan potensi yang mereka miliki supaya lebih berkembang. Oleh karena itu, pemberdayaan pada dasarnya berorientasi pada menggugah kesadaran individu supaya memaksimalkan potensi mereka untuk berusaha terus menerus secara inovatif, tidak berhenti pada zona nyaman mereka (Iskandar and Halim, 2019). 
Melalui pelatihan pemetaan potensi wisata ini, diharapkan pemerintah Kabupaten Maros memperoleh dua keuntungan sekaligus, yaitu (1) Keterlibatan aktif masyarakat sebagai bentuk pemberdayaan agar potensi terpendam yang mereka miliki dapat diaktualisasikan dan berdampak langsung terhadap kehidupan ekonomi mereka. (2) Berkembangnya pariwisata lokal yang juga berdampak terhadap tingkat kesejahteraan masyarakat setempat. Atas dasar pertimbangan inilah, kerjasama pengabdian antara Adpertisi dengan Peemerintah Kabupaten Maros diselenggarakan.

\section{METODE}

Konsep pemberdayaan mengusung dua hasil akhir, yaitu (1) kesadaran, dan (2) gerakan. Oleh karena itulah sebuah pelatihan mengandung dua materi utama, yaitu materi teoretik, dan materi praktik. Untuk mencapai hal tersebut dipergunakan metode ceramah, tanya jawab, diskusi, dan FGD(Soni Fajar Mahmud et al., 2021). Metode cukup efektif dalam menggali gagasan dari masyarakat karena diberi kebebasan mengemukakan apapun yang ada dalam pikiran mereka terkait persoalan sosial yang mereka alami.

Pelatihan pemetaan potensi wisata Kabupaten Maros yang dihadiri oleh kelompok Karang Taruna dan Pemuda Sadar Wisata juga mengusung dua materi utama yaitu teoretik pengetahuan tentang pentingnya pariwisata bagi kehidupan masyarakat Maros khususnya kesejahteraan mereka. Bagian ini berorientasi wawasan agar mereka terlibat membangun pariwisata lokal bersama pemerintah desa. Materi lainnya bersifat praktik yaitu memetakan potensi lokal wisata di desa mereka. Pada bagian praktik ini, kegiatan lebih bersifat FGD berdasarkan Lembaran isian peta potensi wisata yang dibagikan ke peserta.

Target yang diharapkan melalui pelatihan ini khususnya target jangka pendek adalah (1) terbukanya wawasan masyarakat tentang potensi ekonomi pengembangan pariwisata lokal, (2) tumbuhnya kesadaran masyarakat untuk terlibat dan menjadi bagian dalam menggerakkan pariwisata bersama pemerintah, (3) munculnya gagasan dari masyarakat dalam memetakan potensi wisata lokal mereka. Target jangka panjangnya adalah meningkatnya kesejahteraan masyarakat sekitar lokasi wisata.

\section{HASIL DAN PEMBAHASAN}

Asosiasi Dosen Kopertis Indonesia (ADPERTISI) Pusat melakukan kerjasama dengan Pemerintah Daerah Kabupaten Maros dalam hal pengembangan pariwisata, dan salah satunya adalah pelatihan pemetaan potensi wisata lokal berbasis pemberdayaan masyarakat.

Pelatihan berlangsung pada tanggal 4 Agustus 2021 di Aula Kantor Kecamatan Bontoa Kabupaten Maros mulai pkl. 09.00 hingga pkl. 15.00 dengan waktu istirahat sekitar 30 menit. Kegiatan pelatihan dibuka oleh Sekretaris Kecamatan Bontoa sedangkan pihak ADPERTISI diwakili oleh Sekretaris Jenderal Bpk. Ibrahim, SE., Ak. Pemateri pariwisata yaitu Nasrullah dari Universitas Fajar Makassar dan Harifuddin dari Universitas Bosowa Makassar. Jumlah peserta sekitar 15 orang dari kelompok masyarakat dan kelompok Pemuda Sadar Wisata (Darwis), serta Kelompok Karang Taruna. 


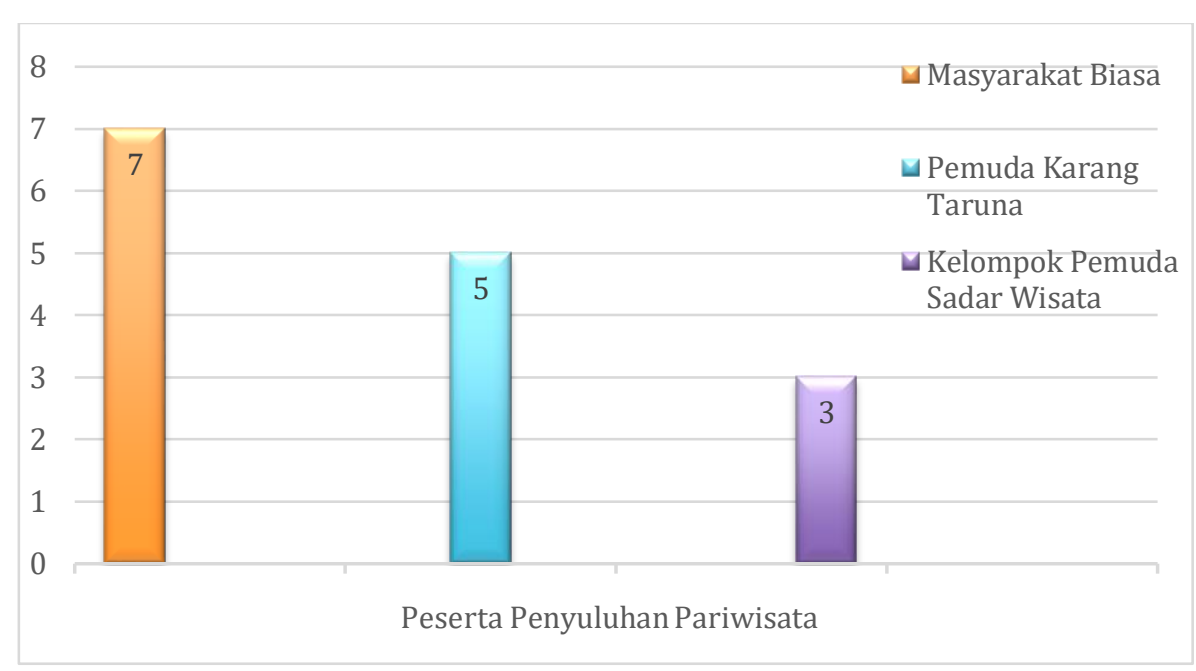

Gambar 1. Grafik Peserta Penyuluhan Pariwisata

Materi pertama dibawakan oleh Harifuddin dengan materi 'Urgensi Pariwisata Dalam Peningkatan Kesejahteraan Masyarakat”. Pada bagian ini, pemateri memberikan pandangan kepadapeserta khususnya masyarakat umum agar memanfaatkan potensi wisata di sekitar mereka yang bisa dijadikan nilai komersial untuk pariwisata. Untuk mewujudkan hal tersebut, masyarakat harus bergerak cepat tanpa harus menunggu pemerintah memulainya. Bila masyarakat mulai lebih dahulu, pemerintah akan tertantang untuk membantu masyarakat. Harifuddin juga menambahkan bahwa saatnya sekarang masyarakat harus mempersiapkan diri dan membenahi obyek wisata. Bila pandemi selesai maka ledakan wisatawan meningkat dan wilayah mereka dikunjungi oleh wisatawan dan itu menghasilkan pendapatan buat mereka.

Materi kedua tentang 'Mewujudkan Desa Wisata' dibawakan oleh Nasrullah. Sesi ini menampilkan strategi membangun desa wisata dan memetakan potensi wisata lokal. Desa wisata yang dimaksud adalah desa yang mengandung tempat menarik (pemandangan alam, pantai, tempat bersejarah, dan sebagainya) kemudian dikelola oleh masyarakat desa sehingga dikunjungi oleh orang lain.Untuk mengetahuinya maka para peserta melakukan pemetaan potensi wisata berupa penginventarisiran hal-hal menarik di desa yang bernilai jual untuk orang luar berkunjung.

Tabel 1. Pemetaan Potensi Wisata Kecamatan Bontoa Maros

\begin{tabular}{lll}
\hline No. & Potensi Wisata & Lokasi \\
\hline 1. & Wisata Sungai & Botolempangan \& \\
2. & Wisata Karst & Botolempangan \\
3. & Wisata Alam/gunung & Rammang-Rammang \\
4. & Wisata Kuliner & Tambua \\
5. & Wisata Goa & Rammang-Rammang \\
6. & Wisata Religius & Tambua \\
\hline
\end{tabular}

Sumber: Hasil FGD, 2021.

Selanjutnya, dalam membangun desa wisata berisikan tentang strategi dan prosedur administrasi online dalam mendaftarkan desa wisata secara online pada 
website pemerintah. Sesi ini menarik perhatian para peserta terutama dari kelompok pemuda pencinta wisata dan kelompok karang taruna. Mereka membutuhkan banyak informasi tentang strategi membangun desa wisata, syarat-syarat desa wisata, stakeholder desa wisata, dan sebagainya.

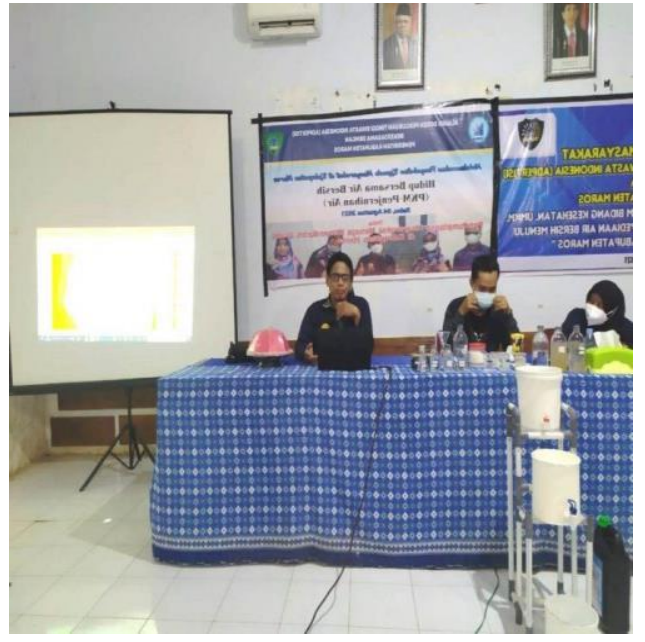

Gambar 2. Penyuluhan

Pariwisata (Admin, 2021)

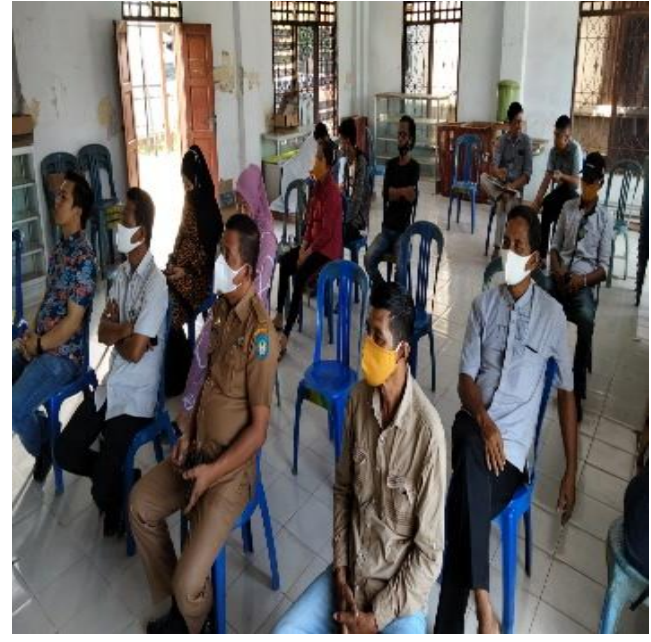

Gambar 3. Peserta Penyuluhan Pariwisata

Selama penyajian materi berlangsung, peserta memperhatikan dengan seksama materi yang disajikan. Pada bagian akhir materi yang langsung dirangkaikan dengan FGD, berlangsung dialog dengan peserta khususnya dari kelompok Pemuda Sadar Wisata (Darwis) dan Pemuda Karang Tarunayang mengajukan sejumlah pertanyaan terkait pengembangan pariwisata. Ternyata, mereka sudah bekerja bersama aparat desa mempersiapkan sebuah lokasi wisata baru sebelum pandemi. Tetapi, semua kegiatan tersebut terhenti sejak pandemi berlangsung. Hal itu juga direspon cepat oleh seorang aparat kecamatan yang menyatakan bahwa kebijakan pemerintah berubah total sejak Pandemi. Hampir semua program pembangunan dialihkan untuk menangani dampak covid di masyarakat.

Pada sesi FGD, terlihat bahwa masyarakat punya keinginan kuat untuk segera keluar dari kondisi hidup yang tidak berubah menjadi lebih baik melalui pengembangan obyek wisata. Melalui FGD ini diperoleh informasi bahwa ada banyak potensi wisata yang dapat mereka kembangkan terutama wisata sungai, wisata kuliner, dan wisata goa, serta wisata religius. Gagasan ini perlu mendapatkan respon dan dukungan dari pihak pemerintah secara material dan moral. Pemerintah juga harus proaktif mendengarkan ide dari bawah yang dapat dilakukan melalui berbagai cara. Intinya, masyarakat merasa diperhatikan. Bila tidak seperti itu, maka masyarakat dapat kembali putus asa dan pasif. 

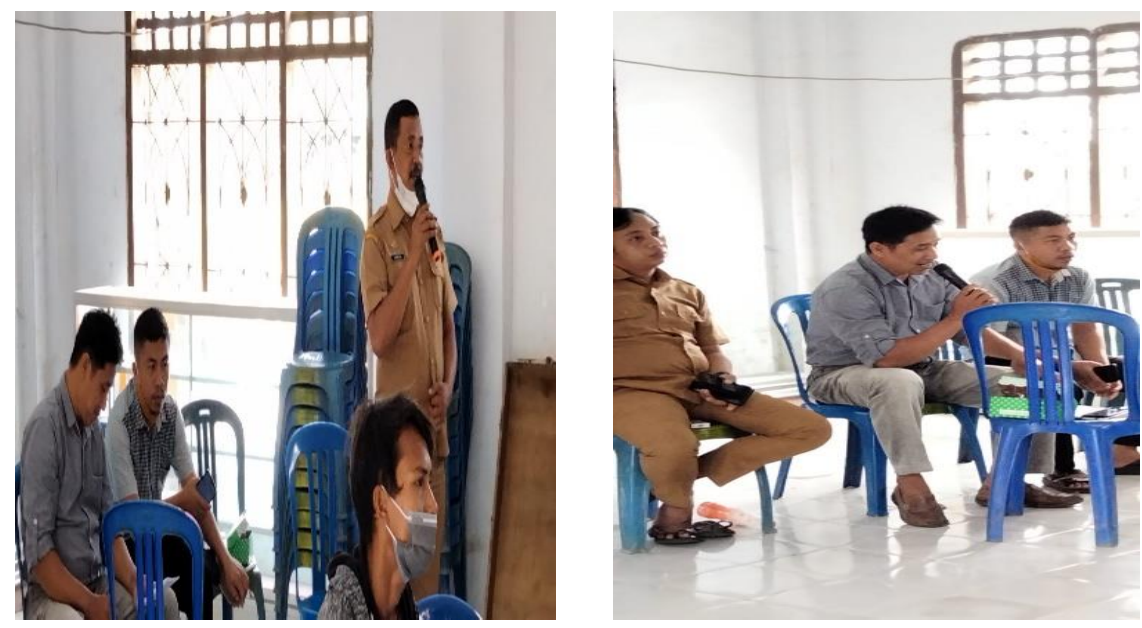

Gambar 4. Tanya Jawab \& FGD (Dokumentasi Peneliti, 2021)

\section{KESIMPULAN}

Pelatihan pemetaan pariwisata di Kecamatan Bontoa menghasilkan dua luaran, yaitu: (1) munculnya banyak gagasan dari masyarakat terkait persoalan sehari-hari yang dialami. (2) terpetakannya potensi wisata di Kecamatan Bontoa.

Pelatihan ini secara jangka pendek berhasil membangun kesadaran masyarakat agar terlibat (berdaya) dalam membangun kehidupan mereka sendiri secara komunal. Persoalan dapat dicarikan jalan keluar bila dipikirkan dan dilakukan secara bersama berbasis kepentingan masyarakat.

ADPERTISI hanya berfungsi sebagai fasilitator masyarakat dengan pemerintah, dan pemerintah harus menindaklanjuti gagasan masyarakat dalam bentuk dukungan konkrit, bisa memperkuat karang taruna dan kelompok pencinta desa wisata, dengan mengadakan pelatihan oleh kelompok lain dan melibatkan mereka dalam kegiatan pariwisata setempat.

\section{UCAPAN TERIMA KASIH}

Terima kasih yang sebesar-besarnya kepada semua pihak yang terlibat baik langsung maupun tidak langsung dalam penyelenggaraan pengabdian masyarakat ini. Terkhusus kepada ADPERTISI yang telah menjadi fasilitator resmi dan Pemerintah Kabupaten Maros yang bersedia menerima peserta pengabdian ini.

\section{DAFTAR PUSTAKA}

A.A.A Ribeka Martha Purwahita, Putu Bagus Wisnu Wardhana, I Ketut Ardiasa, I Made Winia, 2021. Dampak Covid-19 terhadap Pariwisata Bali Ditinjau dari Sektor Sosial, Ekonomi, dan Lingkungan (Sebuah Tinjauan Pustaka). J. Kaji. dan Terap. Pariwisata 1, 68-80. https://doi.org/10.53356/diparojs.v1i2.29

Admin, A., 2021. Gandeng Adpertisi, Dosen Unibos Tingkatkan Pariwisata Maros [WWW Document]. www.fajarpendidikan.co.id. URL https://www.fajarpendidikan.co.id/gandeng-adpertisi-dosen-unibos-tingkatkanpariwisata-maros/ (accessed 10.3.21).

Ananta, H., Rizkon, A., 2020. Analisis dampak Covid-19 terhadap Sektor Pariwisata 
Sikembang Park Kecamatan Blado Kabupaten Batang. Faklutas Ilmu Pendidikan, Fak. Ilmu Sos. Fak. Bhs. Dan Seni, Univrsitas Negeri Semarang 17.

Iskandar, A.M., Halim, H., 2019. Mekanisme Pemberdayaan Gelandangan Dan Pengemis Di Kota Makassar (Studi Kasus Di Perumahan BTP Tamalanrea). Makassar. https://doi.org/10.26618/kjap.v5i2.2236

Ismoyo, B., 2021. Menkop: 22 Persen UMKM yang Berhenti Usaha Akibat Pandemi Covid-19, Kembali Menggeliat [WWW Document]. https://www.tribunnews.com/. URL https://www.tribunnews.com/bisnis/2021/08/05/menkop-22-persen-umkmyang-berhenti-usaha-akibat-pandemi-covid-19-kembali-menggeliat (accessed 10.4.21).

Kendar, K.U., 2021. Wisata aman kebijakan sektor pariwisata di tengah pandemi covid19 [WWW Document]. Kompaspedia.Kompas.id. URL https://kompaspedia.kompas.id/baca/paparan-topik/wisata-aman-kebijakan-sektorpariwisata-di-tengah-pandemi-covid-19 (accessed 1.15.21).

Kinapsi, T.T., 2021. Menyusuri Karst Rammang-Rammang Maros yang Menakjubkan [WWW Document]. Merdeka.com. URL https://www.merdeka.com/travel/menyusuri-pegunungan-karst-rammangrammang-maros-yang-menakjubkan.html (accessed 4.29.21).

Kumparan, K., 2018. Karst Maros Pangkep, Karst Terbesar dan Terindah ke-2 di Dunia [WWW Document]. Kumparan.com. URL https://kumparan.com/kumparantravel/karst-maros-pangkep-karst-terbesar-danterindah-ke-2-di-dunia (accessed 2.18.18).

Poerwanto, E., 2019. Taman Nasional Bantimurung Diakui Jadi ASEAN Heritage Park [WWW Document]. Bisniswisata.co.id. URL https://bisniswisata.co.id/tamannasional-bantimurung-diakui-jadi-asean-heritage-park/

Puspadini, M., 2021. Jelajah Istana Karst Maros, Pegunungan Karst Terbesar Ke-2 di Dunia [WWW Document]. medcom.id. URL https://www.medcom.id/nasional/daerah/0KvggLoN-jelajah-istana-karst-marospegunungan-karst-terbesar-ke-2-di-dunia (accessed 7.30.21).

Redaksi, R., 2021. Maros Akan Bentuk Badan Promosi Pariwisata Daerah [WWW Document]. Matamaros.com. URL https://www.matamaros.com/2021/05/18/marosakan-bentuk-badan-promosi-pariwisata-daerah/ (accessed 5.18.21).

Soni Fajar Mahmud, John Suarlin, Nur Budi Nugraha, 2021. Pelatihan Pemanfaatan Limbah Akar Pohon Hutan Menjadi Hiasan. ABDINE J. Pengabdi. Masy. 1, 34-40. https://doi.org/10.52072/abdine.v1i1.184

Yolanda, F., 2019. Menengok Kerajaan Kupu-Kupu di Bantimurung [WWW Document]. republika.co.id. URL https://www.republika.co.id/berita/pux6jh370/menengokkerajaan-kupukupu-di-bantimurung (accessed 7.20.19). 